\title{
HABITAÇÃO, REGULARIZAÇÃO E REABILITAÇÃO: TENDÊNCIAS EM PORTUGAL E NO BRASIL
}

\author{
HOUSING, LAND REGULARISATION AND URBAN REHABILITATION: TENDENCIES IN \\ PORTUGAL AND IN BRAZIL
}

Dulce Margarida de Jesus Lopes*

\begin{abstract}
Resumo:
O presente artigo faz um paralelo entre o regime jurídico português e o brasileiro em matérias próximas como as da habitação, regularização fundiária e reabilitação. Ainda que em diferentes medidas e com distintos instrumentos, estas problemáticas têm estado na luz da ribalta em ambos os países. E em ambos é notória a dificuldade em concretizar regras de uso, ocupação e transformação do solo em situações em que este já se encontra comprometido, muitas vezes com utilizações de raiz ilegal.

Palavras-chave: Habitação. Regularização fundiária. Reabilitação urbana. Áreas urbanas de génese ilegal. Áreas de reabilitação urbana.
\end{abstract}

\begin{abstract}
:
This article draws a parallel between the Portuguese and the Brazilian legal regimes in areas as closely related as housing, land regularisation and rehabilitation. Although in different measures and with different instruments, these issues have been in the spotlight in both countries. And in both countries it is notorious how difficult it is to put into practice land use rules in situations where that land is already being used, frequently in illegal ways.

Keywords: Housing. Land regularisation. Urban rehabilitation. Urban areas of illegal origin. Urban rehabilitation areas.
\end{abstract}

\section{Tendências em Portugal e no Brasil: breves notas comparativas ${ }^{1}$}

O cruzamento entre habitação, reabilitação e regularização fundiária tem estado cada vez mais em evidência tanto em Portugal como no Brasil, ainda que por motivos distintos.

i. Em Portugal existe um excesso de habitações para o número de habitantes. ${ }^{2}$ De acordo com os Censos de 2011, o número de unidades habitacionais era superior em

Professora da Faculdade de Direito da Universidade de Coimbra; Membro do Instituto Jurídico da Universidade de Coimbra e do Conselho Técnico-Científico do CEDOUA.

1 O presente texto reproduz, com pequenas modificações, a nossa intervenção nas I Jornada Luso-Brasileira de Direito Urbanístico, que tiveram lugar na Faculdade de Direito da Universidade de São Paulo, em 4 de setembro de 2020. Manteremos, por isso, um estilo o mais próximo possível do oral.

2 Algumas razões para o efeito prendem-se com a forte emigração e migrações internas em Portugal, a involução demográfica com a tendência para o envelhecimento e diminuição do número de residentes, o excesso de urbanização viabilizado pelos mecanismos de planeamento urbanístico, a falta de atratividade do 
sensivelmente 45\% ao número de famílias. (PARQUE, 2012). De facto, entre 1970 e 2011, segundo os respetivos censos, o número de alojamentos familiares clássicos passou de 2.702.215 para 5.859.540, representando um crescimento de $116,8 \%$; todavia, este crescimento não foi acompanhado pelo respetivo aumento de famílias clássicas que, para o mesmo período, se registou em $72,4 \%$, crescendo igualmente o número de alojamentos vagos. É neste contexto que a Resolução do Conselho de Ministros n. ${ }^{\circ}$ 48/2015, de 5 de julho, que aprova a Estratégia Nacional para a Habitação para o período de 20152031, refere que a expressão "tanta gente sem casa e tanta casa sem gente" assume uma dimensão nova, pois em Portugal já não existe um défice habitacional (mas uma situação de abundância habitacional) acompanhada, porém, de dificuldades no acesso à habitação. Não obstante, de acordo com um levantamento nacional das necessidades de realojamento habitacional, de fevereiro de 2018, foram identificadas 25.762 famílias como estando em situação habitacional claramente insatisfatória. (PORTUGAL, 2018).

No Brasil, o inverso ocorre. Resultados de 2011 indicam que o défice habitacional caiu no período entre 2007 e 2011 em termos absolutos e relativos, passando de quase 5,6 milhões em 2007 para cerca de 5,4 milhões em 2011, com queda relativa da presença de défice habitacional de 10\% dos domicílios totais em 2007 para 8,8\% em 2011 . $^{3}$ Já em 2015, o défice habitacional estimado corresponde a 6,355 milhões de domicílios. Em relação ao stock de domicílios particulares permanentes e improvisados do país, o défice habitacional corresponde a 9,3\%. (DÉFICIT..., 2018). Mas, em qualquer caso, há insuficiências habitacionais claros em ambos os países, sobretudo para a população de baixa renda, o que permite questionar qual, afinal, o relevo prático do princípio da função social da propriedade e, mais especificamente, da função social da habitação (ou da moradia) para que caminham ambos os ordenamentos jurídicos.

ii. No que se refere à política de reabilitação, em Portugal, a reabilitação urbana tende a ser uma política desejavelmente completa, seja do ponto de vista espacial, seja do ponto de vista funcional. Para além da existência de uma legislação que enquadra esta política (o Decreto-Lei n. ${ }^{\circ}$ 307/2009, de 23 de outubro), a possível localização e extensão de uma área de reabilitação urbana segue critérios muito flexíveis, podendo referir-se ao centro de uma zona urbana com interesse patrimonial ou a uma zona periférica degradada, e podendo visar a reabilitação tanto de áreas para fins habitacionais como de áreas industriais, comerciais ou de serviços degradadas.

mercado de arrendamento, grandemente devido ao histórico congelamento de rendas e ao desinvestimento no locado. Cf., para maiores desenvolvimentos, Dulce Lopes (2018, p. 43-65).

3 Cf. Bernardo Alves Furtado, Vicente Correia Lima Neto, Cleandro Krause (2019, p. 1). 
No Brasil a política de reabilitação tem vindo a ser conceitualmente aplicada a áreas urbanas centrais, ${ }^{4}$ com valor cultural e patrimonial, mas marcadas por um forte abandono e degradação. Nesse sentido foi o Programa de Reabilitação de Áreas Urbanas Centrais - PRAUC - de 2003, que nitidamente se relaciona com objetivos habitacionais, promovendo uma política de "morar no centro". (BRASIL, 2005, p. 9).

Em qualquer dos países, porém, a degradação das cidades, mesmo no seu núcleo central, é uma constante dificilmente reversível.

iii. Em Portugal os problemas de regularização fundiária de grande expressão ("os grandes ilegais") concentram-se em certas áreas localizadas do território nacional, existindo uma única legislação específica vocacionada para a sua resolução (a Lei das Áreas Urbanas de Génese Ilegal, aprovada pela Lei n. ${ }^{o}$ 91/1995, de 2 de Setembro). Contudo, apesar de ser uma legislação excecional e, em princípio, transitória, há muitas áreas urbanas de génese ilegal que ainda não conseguiram ser regularizadas, em especial em face da falta de dinâmica de associação dos interessados e de situações de risco detetadas (por exemplo, movimentos de vertente) aquando dos procedimentos de regularização.

No Brasil multiplicam institutos visando aquela regularização fundiária em face da dimensão e complexidade do problema habitacional. A riqueza da legislação brasileira a este propósito contrasta grandemente com a aparente simplicidade da legislação portuguesa, na medida em que o Estatuto da Cidade e a Lei de Regularização fundiária incluem instrumentos que, de matriz diversa, parecem apreender o fenómeno da regularização fundiária nas suas várias vertentes: a concessão do direito real de uso, a concessão de uso especial para fins de moradia, a usucapião individual e coletiva, as ZEIS - Zonas Especiais de Interesse Social, a legitimação da posse, a legitimação fundiária, novos tipos de loteamento e o direito de laje. ${ }^{5}$

Em qualquer caso, as situações de irregularidade fundiária grassam quer num país quer no outro, ainda que a escalas distintas, e assumindo, a cada momento, feições originais que o legislador dificilmente consegue antecipar e apreender em todos os seus contornos. Havendo ainda, em ambos os Estados, claras deficiências na utilização destes mecanismos do ponto de vista administrativo, notarial, registal e judicial.

$\mathrm{Na}$ impossibilidade de nos podermos debruçar integralmente sobre os enquadramentos jurídicos destas várias políticas nos dois países, iremos centrar-nos de seguida naquele que melhor conhecemos e que melhor podemos dar a conhecer ao público e, agora, aos leitores: o ordenamento jurídico português.

\footnotetext{
$4 \quad$ O conceito de área urbana central não se aplica, porém, apenas aos centros históricos tradicionais, mas também a novas áreas que apresentam similares caraterísticas.

5 Cf., para várias e valiosas perspetivas sobre o tema a obra coletiva (LEITE; MENCIO, 2019).
} 
2. A Política de habitação em Portugal

O Direito à habitação em Portugal, previsto constitucionalmente no art. 65. ${ }^{\circ}$, tem sido objeto de aceso tratamento doutrinário, sobretudo nas últimas décadas, acompanhando a tendência para uma fundamentalização dos direitos, sobretudo tendo por mote a dignidade da pessoa humana e o livre desenvolvimento desta que apenas se cumprem se houver meios materiais para o efeito.

Este direito tipicamente colocado "sob a reserva do possível", ${ }^{6} \mathrm{e}$, portanto, sujeito a uma malha normativa e de proteção menos cerrada do que a aplicável ao direito de propriedade (considerado como um direito análogo aos direitos, liberdades e garantias), tem vindo a ser dogmaticamente valorizado, de acordo com uma ideia de "unidade" subjacente a todos os direitos fundamentais, reconhecendo a necessidade de um nível de proteção similar entre eles e de uma ponderação de direitos (que não se compadece com a pura e simples prevalência dos direitos de liberdade face aos direitos sociais). ${ }^{7}$

Os direitos sociais e, nestes incluídos, o direito à habitação, deixam, por isso, de ser direitos programáticos e não justiciáveis para passarem a ter um conteúdo jurídico mais definido, ${ }^{8}$ impondo obrigações negativas ao Estado e privados (as de não afetar o gozo da habitação e, no caso de entidades públicas, as de não desencadear a remoção de pessoas sem esgotar vias para o seu realojamento) e obrigações positivas ao Estado, tais como as de prover a determinadas necessidades urgentes e imperiosas da população (como sucede com o apoio a pessoas vítimas de violência doméstica ou com o apoio na sequência de catástrofes) e as de, em qualquer caso, definir, prosseguir e concretizar uma política de habitação pensada para fazer face às várias carências habitacionais identificadas.

Isto implica que se assuma de uma vez por todas que a habitação cumpre uma função social relevante (complementar, de certa forma, à função social da propriedade), e que o Estado está necessariamente comprometido com a sua concretização. O que significa que deve este reposicionar-se de modo a encontrar uma posição em que, sem dirigismos mas também sem excessivos liberalismos, adote políticas e medidas concretas que tendam para a satisfação das necessidades habitacionais e que realcem importância pública de se dar um uso efetivo e adequado às habitações existentes.

Em Portugal encontramos a concretização desta política habitacional tendencialmente congruente e consequente num conjunto de diplomas: os aprovados ao abrigo do programa governamental "Uma nova geração de políticas de habitação"

Cf. J. J. Gomes Canotilho (1991, p. 478), “Tomemos a Sério os Direitos Económicos, Sociais e Culturais". Cf., em Portugal, Reis Novais (2010; 2009, p. 229 et seq.); e Carlos Blanco de Morais (2014, p. 60 et seq.).

$8 \quad$ I. E. Koch (2009, p. 14-38). 
(Resolução do Conselho de Ministros n. ${ }^{\circ}$ 50-A/2018, de 2 de maio); seguida por uma alteração ao regime do arrendamento urbano (através da Lei n. ${ }^{\circ}$ 13/2019, de 12 de fevereiro) que visou corrigir situações de desequilíbrio entre arrendatários e senhorios, reforçar a segurança e a estabilidade do arrendamento urbano e proteger arrendatários em situação de especial fragilidade; e, enfim, pela aprovação da Lei de Bases da Habitação (Lei n. ${ }^{\circ}$ 83/2019, de 3 de agosto).

Pela primeira vez é notória uma abordagem global às questões da acessibilidade, adequação, disponibilidade, estabilidade e qualidade da habitação, passando-se de um conceito de habitação para moradia ("from house to home"), e de uma ampliação de foco do local para o "habitat", isto é para a área envolvente e respetivas condições.

A marca de água desta nova aproximação às políticas habitacionais traduz-se numa nova relação (de maior adequação e proporcionalidade) entre as responsabilidades públicas e privadas no mercado habitacional. Os encargos privados no âmbito habitacional sustentam-se no conceito de função social da habitação (conceito este que, aliás, foi explicitamente acolhido na Lei de Bases da Habitação), o que poderá justificar agravamentos fiscais de prédios devolutos, algumas limitações às relações de arrendamento, bem como a possibilidade da intervenção de instrumentos de política urbanística em imóveis privados (como o arrendamento forçado e, mesmo, a expropriação em situações de clarividente interesse público), mas já não poderá sustentar um novo "congelamento" de rendas, como aquele vigente em Portugal durante largos anos. Efetivamente, a função social pode justificar as restrições aos direitos do proprietário que sejam proporcionais numa sociedade democrática e não mais.

Mas, ao mesmo tempo, aquela função social impede que os Estados se desonerem de responsabilidades ativas próprias, remetendo todos os mecanismos de satisfação das necessidades habitacionais para o mercado ou para a sua intervenção no mercado privado. O Estado deve ser o primeiro interveniente na política de habitação, disponibilizando habitação social (através de arrendamento apoiado), promovendo habitação economicamente acessível (e formas de arrendamento como o arrendamento a custos controlados e o arrendamento acessível) e agindo pelo exemplo, não fixando standards e obrigações que ele próprio não cumpre (por exemplo não alienando o seu património mais relevante no mercado, sem pensar nas necessidades habitacionais que deve acautelar). Tradicionalmente, o Estado português não agia diretamente (a habitação social é apenas 3\% da oferta habitacional em Portugal e muitas ainda em bairros periféricos

\footnotetext{
9 A noção de "home” (se quisermos, de moradia), é segundo Fox O’Mahony (2013, p. 159-166), bastante complexa incluindo elementos como o investimento financeiro, a estrutura física, o território, a identidade e o significado social e cultural.
} 
e monofuncionais); hoje, porém, exige-se que o Estado (em particular os Municípios em face do processo de transferência de atribuições em curso) se comprometa em definitivo com a política habitacional, promovendo, entre muitas outras medidas, o uso efetivo de habitações devolutas de propriedade pública ou a elaboração de estratégias ou cartas municipais de habitação que possam, através de recurso facilitado a financiamento, reverter situações de habitação precária e sem qualidade.

E é este paradigma que se pretende instituir em Portugal, em estreita articulação com as políticas específicas da regularização fundiária e da reabilitação urbana. O apelo direto a estas políticas não significa que o direito urbanístico "geral": o dos planos e programas e o das concretas operações urbanísticas, não seja relevante. Todavia, a colocação em marcha de políticas habitacionais consequentes, sobretudo quando incidentes sobre falhas estruturais do mercado, necessita de mecanismos de cariz mais operativo que resolvam, de forma específica e afeiçoada, problemas pré-existentes. No que as políticas de regularização fundiária e de reabilitação podem concorrer.

\section{A Política de regularização fundiária em Portugal}

A necessidade de regularização fundiária para fazer face a situações de informalidade faz-se sentir amiúde em Portugal, sendo necessário recorrer a uma mescla de instrumentos urbanísticos, civis e registais (por exemplo, alterações a loteamentos, acessão e usucapião ou regularização de estremas) para viabilizar o encontro entre a ocupação física do território e a sua configuração jurídica. Todavia, trata-se de fenómenos dispersos pelo território, com motivações e formas de solução (quando possíveis) muito diversas.

Podemos por isso afirmar que uma política de regularização fundiária em Portugal relativamente aos "grandes ilegais" existe apenas quanto às chamadas áreas urbanas de génese ilegal (AUGI), reguladas pela Lei n. ${ }^{\circ}$ 91/1995, de 2 de setembro, com a última alteração introduzida pela Lei n. ${ }^{\circ}$ 70/2015, de 16 de julho. Nas demais situações de concentração de habitação precária, sempre que não seja possível a sua regeneração através da regularização fundiária, a opção passará pelo realojamento (art. $65 .^{\circ}$ da Lei de Bases da Habitação), situação esta que tem sido a mais frequente, até ao momento, em Portugal, marcado por longos anos de planos de realojamento de média e grande dimensão.

A realidade das áreas urbanas de génese ilegal, que se começou a fazer sentir com alguma acuidade já nos anos sessenta, assumiu particular relevo nos anos seguintes à Revolução de 25 de abril, muito devendo à fragilidade da Administração pública de então e à dificuldade de realojamento dos cidadãos nacionais que regressaram, em massa, das ex-colónias. 
Mas, mais, a urbanização clandestina é a faceta física de um fenómeno de transformação social mais amplo, que acompanhou a tendência de procura de casa própria ou, mesmo de segundas residências, por vários segmentos populacionais. ${ }^{10}$ Por isso, as áreas das AUGI são essencialmente compostas por moradias e com uma qualidade edificativa média.

Tendo em vista estas motivações iniciais, que relevam no sentido de se tomar em consideração não só as condições de precariedade em que as construções ilegais eram levadas a cabo, mas também as situações de fragilidade pessoal e familiar que as mesmas coenvolviam, tornou-se imperioso instituir mecanismos específicos que permitissem tornar estas situações claudicantes conformes com um adequado ordenamento urbano.

Note-se que não é apenas o fracionamento físico ilegal - ou a constituição de situações de compropriedade grandemente complexas ${ }^{11}$ - que está aqui em causa. Tratando-se de situações em cascata, como as mesmas não tinham sido antecedidas do necessário loteamento, não poderiam também obter as competentes licenças (ou admissões) de obras de construção, uma vez que não se encontravam preenchidos os pressupostos para a sua concessão (desde logo o da legitimidade sobre o prédio mãe), nem as respetivas autorizações de utilização, o que inviabiliza qualquer ato negocial de compra e venda, arrendamento, constituição de hipotecas ou obtenção de empréstimos sobre os imóveis assim construídos. Foi precisamente para acautelar situações prementes em que a construção era feita sem precedência da prática de qualquer aprovação de loteamento e da realização de obras de urbanização e de edificação, que o legislador veio criar em 1995 um regime excecional de legalização que se destaca pelo complexo jurídico que o compõe e pelo relevo prático que tem tido.

Como se afirma no Acórdão do Supremo Tribunal Administrativo de 22 de fevereiro de 2005 (proferido no processo 0166/04):

a razão de ser do regime excecional de reconversão de áreas urbanas de génese ilegal foi a de permitir às pessoas, normalmente de parcos recursos económicos, ver legalizadas as construções que levaram a cabo para a sua edificação, evitando uma demolição que, em termos normais, seria muito provável, e, por outro lado, permitir a construção em

10 Sobre a evolução do movimento dos clandestinos, respetivas motivações e tipologia dos prédios clandestinos (primeira, segunda habitação, prédios de renda, indústrias e prédios não edificados), cf. J. Gonçalves, Carla Alves e F. Nunes da Silva (2010, p. 161-192).

11 Situações estas que, anote-se, na maioria das vezes têm raízes legais, na medida em que a aquisição de avos ou de quotas ideais da compropriedade não era, nem é, genericamente proibida. Proibida era a construção sem o devido título, a partir da entrada em vigor do Regulamento Geral das Edificações Urbanas, e a construção sem a precedência de loteamento, a partir do Decreto-Lei n. ${ }^{\circ} 400 / 1984$, de 31 de dezembro. A existência de amplas compropriedades o que dificulta, senão mesmo inviabiliza, é a legalização tanto das construções como da divisão fundiária. 
parcelas de terreno adquiridas em que, normalmente, essa construção também não seria possível. Essa possibilidade, há-de, assim, de ser encontrada através da ponderação dos vários interesses em jogo, passando pelo acordo dos vários proprietários, através da cedência, voluntária, ou imposta pela viabilidade do processo, naquilo que seja necessário para a obtenção dos padrões urbanísticos (embora especiais - cfr. artigo $25 .^{\circ}$ da Lei) exigidos. ${ }^{12}$

O âmbito de aplicação do regime jurídico das AUGI incide sobre prédios ou conjunto de prédios contíguos que, sem a competente licença de loteamento, quando legalmente exigida, tenham sido objeto de operações físicas de parcelamento destinadas à construção (até à entrada em vigor do Decreto-Lei n. ${ }^{\circ}$ 400/1984, de 31 de dezembro) loteamentos ilegais, portanto -, desde que os planos municipais em vigor classifiquem a área onde tais operações têm assento como espaço urbano ou urbanizável (art. 1. ${ }^{\circ}$, n. $^{\circ} 2$ ) ou estas correspondam, na sua maioria, a espaços assim classificados e que a área sobrante esteja ocupada maioritariamente com construções destinadas a habitação própria que preencham condições de salubridade e segurança e se encontrem participadas na respetiva matriz à data da entrada em vigor desta $\left(\operatorname{art} .5^{\circ}\right) .^{13}$

Para além de se tratar de um regime excecional, como, aliás, a própria lei o qualifica, de legalização, decorre ainda do art. 57. ${ }^{\circ}$ da Lei n. ${ }^{\circ}$ 91/1995 ser este um regime com uma natureza transitória (ainda que tenha vindo a ser sucessivamente prorrogado), na medida em que apenas se aplica às áreas que, tendo sido delimitadas como tal, disponham de comissão de administração validamente constituída até 31 de dezembro de 2016 (exceto se esta tiver sido eleita nos termos do n. ${ }^{\circ} 4$ do art. 8. $^{\circ}$ ) e de título de reconversão até 30 de junho de 2021.

É por isso, e esta nota é particularmente importante no caso vertente, intenção do legislador que a ilegalidade resultante das AUGI seja resolvida em certo prazo e não mantida indefinidamente, tal como não deve ser mantido ad aeternum o regime excecional previsto no diploma. E, mesmo que o prazo de vigência do diploma das AUGI e das soluções nele constantes venha a ser de novo prorrogado, a verdade é que o mesmo foi criado para viabilizar ou facilitar um objectivo de interesse público (e simultaneamente privado): o da regularização fundiária, sendo que é por via desta que se conseguirá a legalização dos usos e edificações existentes na AUGI ou de outros que aí sejam incluídos, e a conformação destes com os ditames de ordenamento do território e de urbanismo aplicáveis.

12 Para maior descrição desta situação, cf. António José Rodrigues (2010).

13 Exige, porém, o artigo 5. ${ }^{\circ}$ que, neste caso, se tenha de alterar o plano em vigor de modo a que toda a AUGI passe a coincidir com solo classificado como urbano ou urbanizável (n. ${ }^{\circ} 3$ do artigo $5 .^{\circ}$ ). 
Caso não se regularizem as AUGI, como é intenção do legislador, manterse-á uma situação que, como veremos, pode conduzir a situações de indefinição de responsabilidades e a uma indistinção de funções, bem como a um clima de descrédito que já se instalou quanto à concretização de muitos processos de reconversão das AUGI. ${ }^{14}$

Também no que ora interessa, o regime das AUGI é um dos exemplos mais marcantes da interseção entre as regras do direito do urbanismo e das regras jus-civilistas que regem os poderes de disposição da propriedade.

Isto é assim porque a regularização destas áreas de génese ilegal passa, por um lado, pela sua regularização urbanística - através, precisamente, de instrumentos tipicamente urbanísticos como são a operação de loteamento e os planos de pormenor, ainda que as regras a estes aplicáveis (do ponto de vista ambiental, de regras de encargos urbanísticos e de regras de edificabilidade sejam muito mais lassas que as normalmente mobilizáveis) - e, por outro lado, pela regularização fundiária do direito de propriedade (ou de outros direitos fundiários), com apelo a instrumentos típicos de direito civil e de direito processual civil (como é o caso da ação de divisão de coisa comum, ainda que dotada de necessárias especificidades, até porque só pode ser concretizada após a emissão do título de reconversão - cfr. art. $\left.2 .^{\circ}\right) .^{15}$

É a conjugação destes dois tipos de exigências e destes dois tipos de regimes que torna o regime das AUGI altamente complexo e nem sempre de fácil manuseamento. Note-se, porém, que o regime legal não se aplica diretamente a situações de ocupações precárias sem qualquer título, uma vez que nas áreas urbanas de génese ilegal se assume que os proprietários ou comproprietários são titulares de uma posição jurídica que lhes atribui aquela qualidade. Por isso estabelece-se um regime especial de legitimidade no qual a posição do "loteador ilegal" se retrai para dar lugar a quem efetivamente se encontra a ocupar as parcelas, desde que o seu direito esteja devidamente inscrito na conservatória do registo predial competente se trate de donos das construções erigidas na área da AUGI, devidamente participadas na respetiva matriz, bem como os promitentes compradores de parcelas, desde que tenha havido tradição.

14 Sobre o clima de descrédito e desânimo que se instalou na primeira década deste milénio, cf. Isabel Raposo e Ana Valente (2010, p. 225), que o veem como consequência "do arrastar dos processos; da consciência crescente do tempo longo da reconversão, apesar da Lei excepcional; da dificuldade de ultrapassar os entraves urbanísticos (condicionantes e classes de espaço dos Planos Directores Municipais em vigor); da lentidão inerente à complexificação normativa dos instrumentos de gestão territorial; da burocrática teia de legalização fundiária; da rotina repetitiva e pouco estimulante; do cansaço dos proprietários e dos responsáveis das CAC que se consomem em penosos processos burocráticos normativos e jurídicos muitas vezes kafkianos".

15 Para maiores desenvolvimentos sobre estes instrumentos, cf. Fernanda Paula Oliveira e Dulce Lopes (2016). 
São estes proprietários e comproprietários que podem intervir, organizados numa entidade de gestão - a Administração da AUGI - nos processos de reconversão urbanística, desempenhando um papel decisivo na sua concretização.

\section{A Política de reabilitação urbana em Portugal}

De acordo com a noção legislativa de reabilitação urbana no Decreto-Lei

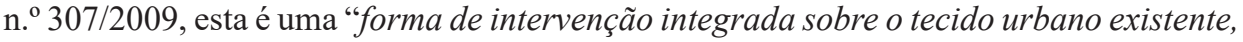
em que o património urbanístico e imobiliário é mantido, no todo ou em parte substancial, e modernizado através da realização de obras de remodelação ou beneficiação dos sistemas de infraestruturas urbanas, dos equipamentos e dos espaços urbanos ou verdes de utilização coletiva e de obras de construção, reconstrução, ampliação, alteração, conservação ou demolição dos edificios" [artigo 2. ${ }^{\circ}$, alínea j); cf., igualmente, a noção mais ampla presente no artigo $61 .^{\circ},{ }^{\circ}{ }^{\circ} 1$, da Lei de bases gerais da política pública de solos, de ordenamento do território e de urbanismo - Lei n. ${ }^{\circ} 31 / 2014$, de 30 de maio - que faz apelo também ao relevo dos serviços de suporte e dos sistemas naturais, bem como de correção de passivos ambientais ou de valorização paisagística).

Em oposição a este conceito ou no outro extremo da intervenção urbanística, encontra-se a realidade da expansão urbana, que, pelo menos do ponto de vista legislativo (pense-se nos novos conceitos de classificação e reclassificação de uso do solo), e na revisão dos instrumentos de planeamento municipal, se encontra em recessão.

Entre estes dois “opostos” há um conjunto de realidades que comungam de algumas das suas características, tendendo umas mais para o entendimento da ocupação urbanística como impondo uma reafetação e reorganização global do território e outras para que essa reafetação ou reorganização seja levada a cabo de forma seletiva, preservando, sempre que possível o existente.

A primeira daquelas formas de intervenção é designada de renovação urbana enquanto "forma de intervenção no tecido urbano existente em que o património urbanístico ou imobiliário é substituído, no seu todo ou em parte, muito substancial". ${ }^{16}$ Esta noção apela para uma atuação de modernização, se não mesmo de demolição e posterior "substituição" do edificado, sendo um processo não apenas físico, mas a mais das vezes também fundiário (alteração predial) funcional (alteração de usos) e social (alteração do tecido social), introduzindo novos elementos estruturantes do aglomerado urbano ou de uma área urbana.

16 Noção acolhida no Decreto Regulamentar n. ${ }^{\circ}$ 9/2009, de 29 de maio. Porém, o Decreto Regulamentar n. ${ }^{\circ}$ $5 / 2019$, de 27 de setembro que o substitui não incluiu este conceito, o que não quer dizer que a realidade urbanística para que apela tenha desaparecido. 
A segunda é designada pelo legislador - e pelo legislador "reforçado", uma vez que o conceito consta do art. 12. ${ }^{\circ}$ e, em particular, do art. 61..$^{\circ}$, n. $^{\circ} 2$, da Lei n..$^{\circ}$ 31/2014, de 30 de maio - de regeneração urbana enquanto "forma de intervenção territorial integrada que combina ações de reabilitação com obras de demolição e construção nova e com medidas adequadas de revitalização económica, social e cultural e de reforço da coesão e do potencial territorial".

O seguinte gráfico demonstra o continuum entre estas várias formas de ocupação territorial, começando com a tendência para a criação de novos espaços urbanos e terminando com a tendência, hoje prevalecente em Portugal, de maior respeito e aproveitamento dos espaços já construídos, de uma forma que respeite ao máximo a sua continuidade e identidade física, económica, social e cultural.

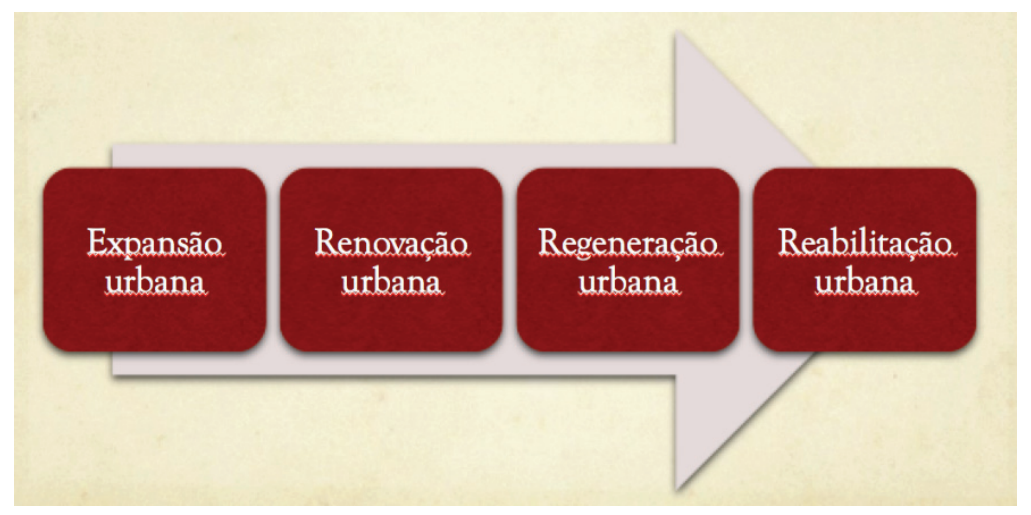

Das noções aqui apresentadas resulta não ser fácil distinguir uma ação de regeneração urbana de uma ação de reabilitação urbana, na medida em que as margens de cada uma delas é indefinida e carece de mediação administrativa na sua determinação em concreto. Isto ainda que o art. 2. $^{\circ}, \mathrm{m}$ ) da Lei n. ${ }^{\mathrm{o}}$ 31/2014 veja a regeneração do território como uma via de promoção da requalificação de áreas degradadas e a reconversão de áreas urbanas de génese ilegal.

Porém, com a equiparação feita a par e passo pela lei de Bases entre estas duas realidades - consideradas ambas como envolvendo claros e primordiais interesses públicos - e a possibilidade de para ambas poderem ser utilizados os mesmos instrumentos jurídicos, desde logo os de política urbanística como a expropriação e a venda forçada, o interesse na distinção perde grande parte do seu relevo.

Mas o mesmo não se diga quanto à distinção entre regeneração e renovação urbana, uma vez que esta última não pode beneficiar dos instrumentos de política urbanística mais impositivos e onerosos aplicáveis à reabilitação (e, por extensão, à regeneração urbana). 
Por isso continua a ser particularmente relevante determinar - seja pela Administração seja eventualmente pelos Tribunais - onde começam e onde terminam estes conceitos, para que se possa determinar quais os poderes e deveres de que os poderes públicos gozam em cada caso. Assim, numa situação de demolição quase integral de edifícios numa área considerável para refuncionalização da mesma, muito difícil será argumentar que o objetivo é o da regeneração urbana e, não o sendo, não será possível o recurso aos instrumentos previstos na lei para as ações de reabilitação e regeneração, assim como terá de ser fundamentada de forma muito concreta e circunstanciada a necessidade de uma tal intervenção negativa sobre os direitos ou expectativas legítimas dos interessados.

A reabilitação e regeneração urbanas são particularmente importantes no novo enquadramento da política habitacional, como é evidente do disposto no art. $36 .^{\circ}$ da Lei de Bases da Habitação. Aliás, os instrumentos mais relevantes em matéria habitacional encontram-se hoje voltados não para a expansão urbana (novas áreas sociais) nem sequer para a renovação urbana (a alteração profunda de áreas existentes para as destinar a usos sociais $\left.{ }^{17}\right)$, mas sim para a reabilitação urbana.

Pense-se, por exemplo no programa reabilitar para arrendar que tem como objetivo o financiamento de operações de reabilitação de edifícios com idade igual ou superior a 30 anos, que, após reabilitação, deverão destinar-se predominantemente a fins habitacionais, para arrendamento em regime de renda condicionada. ${ }^{18}$

É certo que esta reabilitação pode referir-se apenas à reabilitação de edifícios individualmente considerados, mas o ideal é que a política de habitação seja cruzada com uma política de reabilitação urbana global e integrada, com propósitos mais amplos do que a mera recuperação física do imóvel, uma vez que também a revitalização da área envolvente é importante para a melhoria do "habitat" residencial.

E, de facto, o Regime Jurídico da Reabilitação Urbana aponta para uma nova forma de agir administrativo já que a reabilitação urbana deve, preferencialmente, assentar em áreas de reabilitação urbana (ARU) - que, de acordo com a definição que delas é feita, são potencialmente extensíveis a todos os espaços urbanos (do centro às periferias), posto que os respetivos processos de degradação e declínio assim o justifiquem - para as quais se aprovam operações de reabilitação urbana (ORU) - que obrigam sempre a uma visão de conjunto ainda que se trate de uma ORU simples, já que são definidas como o conjunto

17 Tem ocorrido, por vezes, o inverso. A demolição de bairros sociais, como o Bairro do Aleixo, no Porto, com realojamento dos ocupantes, para dar lugar a outras ocupações económicas e sociais no local de grande centralidade naquela cidade.

18 Visa-se aqui tanto abrir novas oportunidades habitacionais para segmentos da população que têm menos possibilidades de acesso como contrariar a tendência de colocar a reabilitação ao serviço de atividades relacionadas com atividades turísticas ou similares, como o alojamento local. 
articulado de intervenções visando, de forma integrada, a reabilitação urbana de uma determinada área - que devem ser realizadas de acordo com uma estratégia de reabilitação urbana (se a ORU for simples) ou um programa estratégico de reabilitação (se a ORU for sistemática). Instrumentos estes cujo conteúdo, ao contrário do que o nome indica, não se destinam a definir uma estratégia (no sentido de grandes desígnios ou objetivos a concretizar e finalidades a potenciar), mas a programar a execução da ORU devendo, por isso, conter, nos seus traços gerais, as caraterísticas e funções daquela programação.

Refira-se que a reabilitação urbana (simples ou sistemática) em áreas de reabilitação urbana pressupõe sempre e imprescindivelmente uma decisão complexa que integre a delimitação da área, a aprovação da operação de reabilitação e a respetiva estratégia ou programa estratégico: só se poderá aplicar o regime integral previsto no regime jurídico da reabilitação urbana (RJRU), designadamente quanto ao desencadeamento das modalidades e dos instrumentos de execução nele previstos, quando, para além de delimitada a área de atuação, tiver sido aprovada a respetiva operação de reabilitação com os seus "instrumentos estratégicos".

Na versão inicial do RJRU, estas decisões eram tomadas em simultâneo: a definição (aprovação) de uma área de reabilitação urbana não correspondia à mera identificação da área territorial sobre a qual seria promovida uma operação de reabilitação urbana; pelo contrário: traduzia-se sempre numa decisão de conteúdo complexo que integrava obrigatoriamente a identificação dos concretos limites físicos da área a sujeitar à operação de reabilitação urbana; a determinação do tipo de operação a concretizar; a definição da entidade gestora; a fixação dos objetivos a alcançar com a operação e a determinação dos "instrumentos" programáticos (estratégicos) que a orientam (enquadram), isto é, a estratégia ou o programa estratégico de reabilitação urbana. ${ }^{19}$

Com a Lei n. ${ }^{\circ}$ 32/2012, que alterou o Decreto-Lei n. ${ }^{\circ}$ 307/2009, veio permitir-se (mas não impor-se), que a decisão complexa (traduzida num conjunto de decisões parcelares ou preliminares anteriormente referidas) seja faseada, procedendose primeiro à identificação dos concretos limites físicos da área a sujeitar à operação de reabilitação urbana (art. 13. ${ }^{\circ}$ ), apenas depois se aprovando essa operação (art. $16^{\circ}{ }^{\circ}$ ), aprovação que integra, para além da definição do tipo de operação a realizar, também a estratégia ou programa estratégico a concretizar.

Pretendeu-se, com esta alteração, promover, o mais antecipadamente possível, a reabilitação de edifícios e frações em área de reabilitação urbana pelos seus proprietários (mesmo antes da aprovação de uma operação de reabilitação para a mesma), já que a delimitação daquela área tem como efeitos a definição, pelo município, dos

$\overline{19}$ Cfr. Fernanda Paula Oliveira, Dulce Lopes e Cláudia Alves (2011), comentário ao artigo $13 .{ }^{\circ}$ 
benefícios fiscais associados aos impostos municipais sobre o património, designadamente o imposto municipal sobre imóveis e o imposto municipal sobre as transmissões onerosas de imóveis, nos termos da legislação aplicável e a concessão aos proprietários e titulares de outros direitos, ónus e encargos sobre os edifícios ou frações nela compreendidos do direito de acesso aos apoios e incentivos fiscais e financeiros à reabilitação urbana, nos termos estabelecidos na legislação aplicável, sem prejuízo de outros benefícios e incentivos relativos ao património cultural. ${ }^{20}$

Porém, a delimitação de uma ARU é apenas um primeiro passo de um processo longo no âmbito do qual o município tem de programar a respetiva execução: é nisso, repetimo-lo, em que consiste a elaboração da estratégia ou do programa estratégico da reabilitação urbana: programar a execução e não definir uma "estratégia" ou planear.

Do que acabamos de afirmar decorre que a delimitação de uma ARU é apenas um passo (inicial) de um longo e complexo processo. Não deixa, no entanto, de ser um passo importante sendo fundamental, desde logo, que essa área seja devidamente selecionada e delimitada: caso não o seja, corre-se o sério risco de o processo ficar a meio caminho. Não se pode esquecer que o que se está a fazer, quando se delimita a ARU, é a identificar uma área para executar, execução essa que terá de ficar devida e previamente programada.

Em qualquer caso, o que se tem assistido é que, passados estes três anos, muitas ORU não foram aprovadas - eventualmente pelo privilégio que se tem dado à reabilitação de edifícios e pela prioridade que se tem deferido à elaboração de instrumentos de programação pensados sobretudo para o acesso a mecanismos de financiamento. De facto, tem havido nos anos mais recentes uma opção deliberada para equiparar o mais possível a reabilitação urbana e reabilitação de edifícios, o que, nalguns casos, pode surtir os efeitos desejados, uma vez que pode haver investimentos/intervenções charneira em edifícios com elevada centralidade e valor e que podem ter amplos efeitos irradiadores no território (spill-over effects). Contudo, tal não deve fazer esmorecer a importância de uma adequada política de reabilitação urbana, quando muito que nos instrumentos

20 À critica que poderia ser feita a esta solução 3/4 de a intervenção nos edifícios ou frações integradas numa área de reabilitação urbana sem que esteja ainda aprovada a respetiva estratégia ou programa estratégico (que apenas ocorrerão em momento posterior, aquando da aprovação da operação de reabilitação urbana), poderem vir a ser um obstáculo à concretização daquela "estratégia"3/4 respondeu a presente Lei com a exigência de que a aprovação da área de reabilitação urbana seja acompanhada de uma memória descritiva e justificativa, que inclua não apenas os critérios subjacentes à respetiva delimitação territorial, mas também os objetivos estratégicos a prosseguir e que funcionam, deste modo, como uma antecipação da estratégia ou programa estratégico a desenvolver (condicionando, simultaneamente, o conteúdo destes "documentos”). Todavia, segundo nos é dado a constatar, nem sempre a delimitação das ARU (sem ORU) inscrevem um pensamento próprio sobre a reabilitação, o que pode contribuir para a consolidação de situações de reabilitação (de edifícios) desajustadas com as reais necessidades de reabilitação urbana municipal. 
de estratégia desta sejam claramente identificados quais são os edifícios base ou fulcrais (públicos ou privados) a reabilitar e em que termos.

Só assim se conseguirá fazer face a necessidades habitacionais prementes de forma estruturada e não apenas a situações individuais que podem não corresponder às mais necessitadas de intervenção.

\section{Reflexões finais}

Analisado sucintamente o enquadramento normativo em Portugal, é de concluir que o mesmo tende a ser bastante completo, incluindo legislação de base em qualquer uma das três políticas consideradas: habitação, regularização e reabilitação. O pressuposto da sua aplicação é, no entanto, bastante exigente no sentido de que a satisfação dos requisitos urbanísticos (por muito que possam ser de natureza especial) continua a funcionar como requisito prévio às possibilidades de regularização fundiária ou de reabilitação do edificado e, bem assim, de uma afetação estável e formal ao uso habitacional.

Há, portanto, uma pretensa unidade "perfeita" do sistema jurídico português entre os requisitos provenientes de várias vertentes do Direito, mas que o torna dificilmente exequível, pois basta que um deles falhe para que o sistema se desmorone.

Se nos é permitida uma última comparação com o enquadramento normativo brasileiro, este conta com instrumentos jurídicos em maior número, sensivelmente mais originais e que permitem uma maior flexibilidade, ao se ter recentemente dissociado regularização urbanística e regularização fundiária, fazendo "prevalecer" esta (o direito à formalidade e aos títulos de "propriedade") sobre aquela (as condições físicas e urbanísticas da moradia). ${ }^{21}$ E se este sistema parece ser, de facto, mais exequível do que o português, não deixa de suscitar dúvidas sobre o tipo de resultados práticos a que se venha a chegar.

Coimbra, agosto de 2020.

21 Cf. Janaína Rigo Santin e Rafaela Comiran (2018, p. 1.609). 


\section{Referências}

BRASIL. Ministério das Cidades. Reabilitação de centros urbanos. Coordenação geral de Raquel Rolnik e Renato Balbim. Brasília: Ministério das Cidades, dez. 2005. Disponível em: https:// bibliotecadigital.seplan.planejamento.gov.br/bitstream/handle/iditem/289/Reabilitacao_Centros_ SNPU_2006.pdf? sequence $=1 \&$ isAllowed $=\mathrm{y}$.

CANOTILHO, José Joaquim Gomes. Boletim da Faculdade de Direito da Universidade de Coimbra: estudos em homenagem ao prof. Doutor Ferrer-Correia, Coimbra, v. 3, p. 461-500, 1991.

DÉFICIT habitacional no Brasil 2015. Fundação João Pinheiro, Diretoria de Estatística e Informações. Belo Horizonte: FJP, 2018. (Estatística \& Informações; n. 6). Disponível em: https://antigo.mdr. gov.br/images/stories/ArquivosSNH/ArquivosPDF/Publicacoes/capacitacao/publicacoes/deficithabitacionalBrasil_2015.pdf.

FOX O'MAHONY, Lorna. The meaning of home: from theory to practice. International Journal of Law in the Built Environment, West Yorkshire, v. 5, n. 2, p. 159-171, 2013.

FURTADO, Bernardo Alves; LIMA NETO, Vicente Correia; KRAUSE, Cleandro. Nota técnica: estimativas do déficit habitacional brasileiro (2007-2011) por municípios (2010). Brasília: Ipea, maio 2013. Disponível em: http://repositorio.ipea.gov.br/bitstream/11058/5809/1/NT_n01_Estimativasdeficit-brasileiro-2007-2011-municipios-2010_Dirur_2013-maio.pdf.

GONÇALVES, Jorge; ALVES, Carla M.; SILVA, Fernando Nunes da. Do ilegal ao formal: percursos para a reconversão urbana das áreas urbanas de génese ilegal em Lisboa. In: BÓGUS, Lucia; RAPOSO, Isabel; PASTERNAK, Suzana (org.). Da irregularidade fundiária urbana à regularização: análise comparativa Portugal-Brasil. São Paulo: EDUC, 2010. p. 161-192.

$\mathrm{KOCH}$, Ida Elisabeth. Human rights as indivisible rights: the protection of socio-economic demands under the European convention on human rights. Leiden: Martinus Nijhoff Publishers, 2009. p. 1438 .

LEITE, Luis Felipe Tegon Cerqueira; MENCIO, Mariana (coord.). Regularização fundiária urbana: desafios e perspectivas para aplicação da Lei n. 13 465/2017. Mauá: Letras Jurídicas, 2019.

LOPES, Dulce. Empty homes and needy people: time for a new housing policy in Portugal and elsewhere? In: VOLS, Michel; SIDOLI, Julian. People and buildings: comparative housing law (ed.). The Hauge: Eleven International Publishing, 2018. p. 43-65.

MORAIS, Carlos Blanco de. De novo a querela da "unidade dogmática" entre direitos de liberdade e direitos sociais em tempos de "exceção financeira". e-Pública: Revista Eletrónica de Direito Público, Lisboa, v. 1, n. 3, p. 59-85, 2014. Disponível em: http:/www.scielo.mec.pt/pdf/epub/v1n3/ v1n3a05.pdf.

NOVAIS, Jorge Reis. Direito, liberdade e garantia: uma noção imprestável na justiça administrativa? Cadernos de Justiça Administrativa, Coimbra, n. 73, jan./fev. 2009. 
NOVAIS, Jorge Reis. Direitos sociais: teoria jurídica dos direitos sociais enquanto direitos fundamentais. Coimbra: Coimbra Editora, 2010.

OLIVEIRA, Fernanda Paula; LOPES, Dulce. As áreas urbanas de génese ilegal (AUGIs) no contexto da "política" de legalização. Coimbra: Almedina, 2016.

OLIVEIRA, Fernanda Paula; LOPES, Dulce; ALVES, Cláudia. Regime jurídico da reabilitação urbana: comentado. Coimbra: Almedina, 2011.

PARQUE habitacional em Portugal: evolução na última década 2001-2011. Destaque, Lisboa, 7 dez. 2012. Disponível em: https://www.ine.pt/ngt_server/attachfileu.jsp?look_ parentBoui=149571899\&att_display $=$ n\&att_download $=\mathrm{y}$.

PORTUGAL. Decreto Regulamentar n. ${ }^{0}$ 5/2019. Procede à fixação dos conceitos técnicos atualizados nos domínios do ordenamento do território e do urbanismo. Diário da República, Lisboa, $1^{a}$ série, n. 186, p. 7-9, 27 set. 2019. Disponível em: https://dre.pt/application/conteudo/125009062.

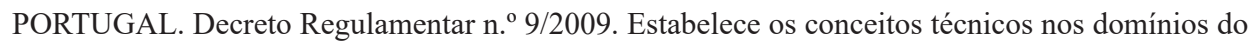
ordenamento do território e do urbanismo. Diário da República, Lisboa, $1^{\text {a }}$ série, n. 104, p. 3.3663.367, 29 maio 2009. Disponível em: https://dre.pt/application/conteudo/494182.

PORTUGAL. Decreto-Lei n. ${ }^{\circ} 400 / 84$. Estabelece o novo regime jurídico das operações de loteamento urbano e revoga o Decreto-Lei n. ${ }^{\circ}$ 289/73, de 6 de Junho (no uso da autorização legislativa conferida ao Governo pela Lei n. ${ }^{\circ}$ 25/84, de 13 de Julho). Diário da República, Lisboa, $1^{\text {a }}$ série, n. 301, p. 3.946-3.960, 31 dez. 1984. Disponível em: https://dre.pt/application/conteudo/389826.

PORTUGAL. Instituto da Habitação e da Reabilitação Urbana. Levantamento nacional das necessidades de realojamento habitacional. [S. l.]: IHRU, fev. 2018. Disponível em: https://www. portaldahabitacao.pt/opencms/export/sites/portal/pt/portal/habitacao/levantamento_necessidades_ habitacionais/Relatorio_Final_Necessidades_Realojamento.pdf.

RAPOSO, Isabel; VALENTE, Ana. Diálogo social ou dever de reconversão? As áreas urbanas de génese ilegal (AUGI) na área metropolitana de Lisboa. Revista Crítica de Ciências Sociais, Coimbra, v. 91, p. 221-235, 2010.

RODRIGUES, António José. Loteamentos ilegais: áreas urbanas de génese ilegal: AUGI. 4. ed. Coimbra: Almedina, 2010.

SANTIN, Janaína Rigo; COMIRAN, Rafaela. Direito urbanístico e regularização fundiária. Revista de Direito da Cidade, Rio de Janeiro, v. 10, n. 3, p. 1.595-1.621, 2018. 
